\title{
Whole body vibrations during field operations in the vineyard
}

\author{
Pietro Catania, ${ }^{1}$ Mariangela Vallone, ${ }^{1}$ Maria Alleri, ${ }^{1}$ Giuseppe Morello, ${ }^{1}$ Giuseppe Spartà, ${ }^{2}$ \\ Pierluigi Febo ${ }^{1}$
}

\author{
'University of Palermo. Dipartimento di Scienze Agrarie e Forestali, Palermo, italy \\ ${ }^{2}$ Assessorato Regionale Risorse Agricole e Alimentari, Palermo, Italy
}

\section{Abstract}

Human exposure to mechanical vibration can be a significant risk factor for exposed workers and this also occurs in the agricultural sector, in particular with reference to the driver of the tractor during field operations. The aim of this paper is the evaluation of Whole Body Vibrations for the operator driving tractors during the field operations in the vineyard. The experimental tests were performed using a wheeled and a track-laying tractor. They were coupled to four different machines: rototilling (RT), chisel plough (CP), flail mowers (FM) and vibro farmer (VF). Two homogeneous plots of vineyard, about $200 \mathrm{~m}$ long, were identified different only for slope: $0 \%$ and $30 \%$. The tests were performed during the execution of the cultivation operations in flat conditions, uphill and downhill. For the evaluation of whole-body vibration we referred to ISO 2631-1:2008 standard. We used the portable vibration analyzer HD2070 by Delta $0 \mathrm{hm}$, Italy. The mean square frequency-weighted acceleration $\left[\mathrm{m} \mathrm{s}^{-2}\right.$ ] was evaluated along each of the three axial components of the acceleration vector $\left(\mathrm{a}_{\mathrm{wx}}, \mathrm{a}_{\mathrm{wy}}, \mathrm{a}_{\mathrm{wz}}\right)$

$$
\mathrm{a}_{\mathrm{w}}=\left[\frac{1}{\mathrm{~T}} \int_{0}^{\mathrm{T}} \mathrm{a}_{\mathrm{w}}^{2}(\mathrm{t}) \mathrm{dt}\right]^{1 / 2}
$$

The vibration total value to which the body is exposed $\left(a_{v}\right)$ was determined by the following relationship:

Correspondence: Pietro Catania, University of Palermo. Dipartimento di Scienze Agrarie e Forestali Viale delle Scienze Edificio 4, 90128 Palermo, Italy.

Tel. +39.91 .23865608 .

E-mail: pietro.catania@unipa.it

Key words: safety, tractor, whole body vibration.

Contributions: the authors contributed equally.

Conflict of interests: the authors declare no potential conflict of interests.

Conference presentation: part of this paper was presented at the $10^{\text {th }}$ Italian Conference AIIA (Associazione Italiana di Ingegneria Agraria), 2013 September 8-12, Viterbo, Italy.

(C) Copyright P. Catania et al., 2013

Licensee PAGEPress, Italy

Journal of Agricultural Engineering 2013; XLIV(s2):e143

doi:10.4081/jae.2013.s2.e143

This article is distributed under the terms of the Creative Commons Attribution Noncommercial License (by-nc 3.0) which permits any noncommercial use, distribution, and reproduction in any medium, provided the original author(s) and source are credited. $\mathrm{a}_{\mathrm{v}}=\left(k x^{2} a w x^{2}+k y^{2} a w y^{2}+k z^{2} a w z^{2}\right)^{1 / 2}$

where $\mathrm{kx}=\mathrm{ky}=1.4$ and $\mathrm{kz}=1$.

The study allowed to point out that during the use of the above mentioned operating machines coupled both with a track-laying tractor and a wheeled tractor, $\mathrm{A}(8)$ values were always higher than $0.5 \mathrm{~m} \mathrm{~s}^{-2}$ therefore, included in the "risk threshold" identified by the Italian Law Decree 81/2008. The machines coupled to the wheeled tractor always registered higher vibration values on the driving seat than the same machines coupled to the tracklying tractor. The operating machines showing higher vibration values are rototilling and vibro farmer in both tractors. Finally, the soil conditions in terms of slope caused no particular differences of vibration levels for all the machines used in the tests.

\section{Introduction}

Human exposure to mechanical vibration may represent a significant risk factor for exposed workers in the agricultural sector, with particular reference to the operators driving tractors (Lines et al., 1995; Matthews, 1966, Pessina et al., 2012, Scarlett et al., 2007).

The growing relevance of this risk in Europe and in the industrialized countries, both in terms health risk, and in terms of economic damage, led to the drafting of regulations and specific measures to reduce it. Directive 2002/44/EC of 25 June 2002 "on the minimum health and safety requirements regarding the exposure of workers to the risks arising from physical agents (vibration)" is the key step to ensure the implementation of specific protection measures for the prevention of risk exposure to vibration in the workplace.

This study would be a useful tool for users of machines and equipment that may result in exposure to vibrations within the agricultural sector in order to be in line with the provisions of the regulations on safety in the workplace.

The aim of the research was to assess the risk of exposure to wholebody vibration for the operator driving a wheeled and a tracklaying tractor during the execution of some agricultural operations carried out in the vineyard.

\section{Materials and methods}

\section{Farm and experimental tests}

The tests were carried out in a farm situated in the countryside of Santa Margherita Belice (province of Agrigento, Sicily).

The tests consisted in the evaluation of vibration values on the driving seat of a wheeled tractor (tractor A) and a tracklaying tractor (tractor B) during the execution of some agricultural operations with four different machines: rototilling (RT), chisel plough (CP), flail mowers (FM) and vibro farmer (VF). 
Two homogeneous plots of vineyard, about $200 \mathrm{~m}$ long, were identified different only for slope: $0 \%$ and $30 \%$. The tests were performed during the execution of the cultivation operations in the following conditions:

- $\quad$ flat, test named T1;

- $\quad$ uphill, test named T2;

- downhill, test named T3.

distinguishing between the tests performed with the wheeled tractor, known respectively as T1-A, T2-A and T3-A and those carried out with the tracklaying tractor, respectively called T1-B, T2-B and T3-B.

The average forward speed of the tractor was $2.5 \mathrm{~km} / \mathrm{h}$ in test T2 and $3.0 \mathrm{~km} / \mathrm{h}$ in tests T1 and T3.

\section{Machines used in the tests}

The tractors used during the tests are (Figure 1):

- the wheeled tractor Star 75 by Goldoni, named A, specialized for orchard and vineyard, $55 \mathrm{~kW}$ power, John Deere engine complete with soundproof cab and air conditioning (Table 1);

- $\quad$ the track-laying tractor Trekker $80 \mathrm{~F}$ by Landini, named B, without cab, equipped with an anti-tip device, $58 \mathrm{~kW}$ power, Perkins engine 1104D-44 (Table 1).

Table 2 shows the characteristics of the machines used to carry out the tests (Figure 2).

\section{Instruments used during the tests}

For vibration measurements, a triaxial piezoelectric accelerometer, a signal conditioner, a digital archiving system, a frequency analyzer, connecting cables and a calibrator were used. The tests were performed according to ISO 2631-1, 2008. It defines standardized methods of measuring whole body vibration and provides some guidelines for the assessment of health effects.

The frequency spectrum and the direction and intensity of the acceleration were taken into account for the assessment of exposure to whole-body vibration.

IS0 2631-1: 2008 regulation defines the coordinate systems for accelerations measurement according to the entry point of the vibrations while keeping the axes $\mathrm{x}, \mathrm{y}$ and $\mathrm{z}$ always in the same direction but with different origin according to the operator's position.

In whole-body vibration the $\mathrm{z}$ (vertical) axis is directed in the direction of the spinal column so this direction is the most dangerous for the drivers. Acceleration levels were measured as frequency-weighted root mean square values, in the frequency range $0.5-80 \mathrm{~Hz}$. The measurements were made by inserting the triaxial accelerometer between the seat and the operator (Figure 3).

The accelerations (aw) detected on the $\mathrm{x}$ and $\mathrm{y}$ axes were further weighted by a factor of 1.4 .

During the tests we used the portable vibration analyzer HD2070 by

Table 1. Main technical characteristics of the tractors used in the tests.

\begin{tabular}{|c|c|c|c|c|c|c|c|}
\hline Tractor & Manifacturer & $\begin{array}{l}\text { Mass } \\
{[\mathrm{kg}]}\end{array}$ & $\begin{array}{l}\text { Wheel track } \\
\text { [mm] }\end{array}$ & $\begin{array}{l}\text { Wheelbase } \\
\text { [mm] }\end{array}$ & $\begin{array}{l}\text { Seat b1 b2 h } \\
{[\mathrm{cm}]}\end{array}$ & Year & $\begin{array}{l}\text { Hours of work } \\
\text { [n] }\end{array}$ \\
\hline A & Goldoni & 2700 & 1800 & 1900 & $42 \times 39 \times 41$ & 2005 & 4480 \\
\hline B & Landini & 3800 & 1650 & - & 40x41x39 & 2005 & 4390 \\
\hline
\end{tabular}

Table 2. Main technical characteristics of the machines used in the tests.

\begin{tabular}{lccccc} 
Machine & $\begin{array}{c}\text { Mass } \\
{[\mathrm{kg}]}\end{array}$ & $\begin{array}{c}\text { Width } \\
{[\mathrm{m}]}\end{array}$ & $\begin{array}{c}\text { Length } \\
{[\mathrm{m}]}\end{array}$ & $\begin{array}{c}\text { Tillage depth } \\
{[\mathrm{m}]}\end{array}$ & $\begin{array}{c}\text { Working tools } \\
{[\mathrm{n}]}\end{array}$ \\
Chisel plough & 350 & 1.80 & 0.8 & 0.12 & 5 \\
Vibro farmer & 410 & 1.80 & 1.4 & 0.12 & 11 \\
\hline Rototilling & 400 & 1.80 & 0.5 & 0.12 & 36 \\
Flail mowers & 495 & 1.80 & 0.85 & 0.00 & 14 \\
\hline
\end{tabular}
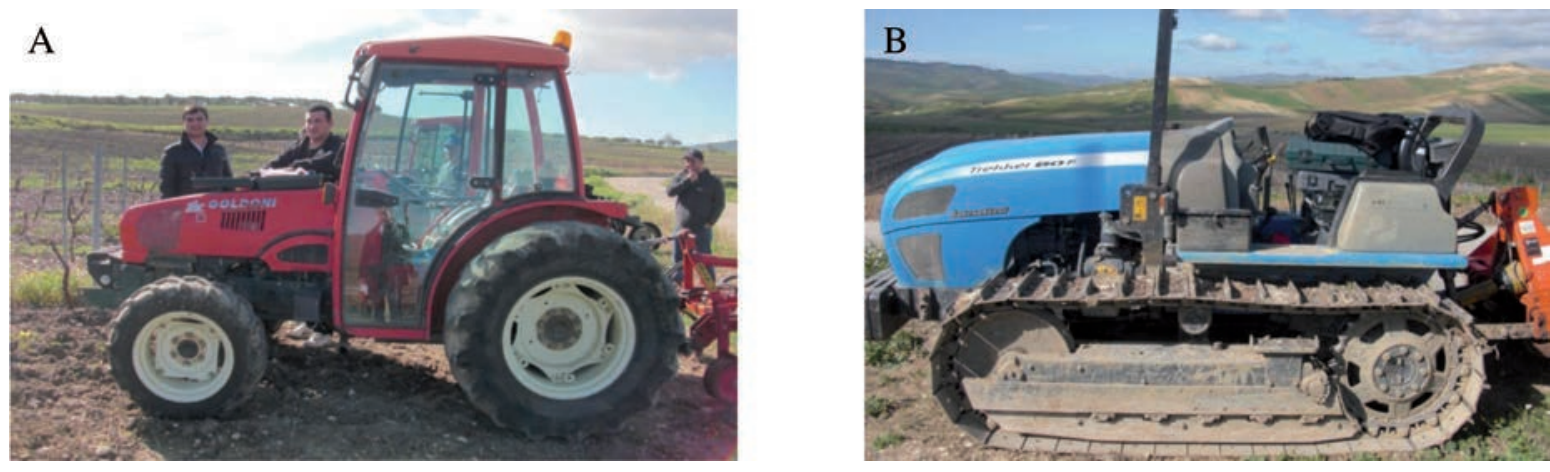

Figure 1. Wheeled and tracklaying tractors used in the tests. 
Delta Ohm, Italy (Fig.4). It is able to perform spectral analysis and statistics simultaneously on three channels.

The mean square frequency-weighted acceleration $\left[\mathrm{m} \mathrm{s}^{-2}\right]$ was evaluated along each of the three axial components of the acceleration vector (awx, awy, awz):

$$
a_{w}=\left[\frac{1}{T} \int_{0}^{T} a_{w}^{2}(t) d t\right]^{1 / 2}
$$

The total vibration value to which the body is exposed $\left(\mathrm{a}_{\mathrm{v}}\right)$ was determined by the following relationship:

$a_{v}=\left(k x^{2} a_{w x}^{2}+k y^{2} a_{w y}^{2}+k z^{2} a_{w z}^{2}\right)^{1 / 2}$

where $\mathrm{kx}=\mathrm{ky}=1.4$ and $\mathrm{kz}=1$.

Acceleration data were correlated with the actual time of exposure in order to calculate the vibration risk assessment.

\section{Results and discussion}

\section{Tests performed with the wheeled tractor}

\section{Wheeled tractor in flat (test T1-A)}

Figure 5 shows that the highest aw value is obtained on the $\mathrm{z}$ axis for all the machines. In particular, RT provided the highest $\mathrm{z}$-axis value $\left(0.94 \mathrm{~m} / \mathrm{s}^{2}\right)$, then FM $\left(0.70 \mathrm{~m} / \mathrm{s}^{2}\right), \mathrm{VF}\left(0.63 \mathrm{~m} / \mathrm{s}^{2}\right)$ and CP $\left(0.63 \mathrm{~m} / \mathrm{s}^{2}\right)$. Note that RT gave values higher than $30 \%$ respect to $\mathrm{CP}$ and VF. With regard to total $\mathrm{a}_{\mathrm{v}}$ value, RT gave $1.42 \mathrm{~m} / \mathrm{s}^{2}$, then CP $1.04 \mathrm{~m} / \mathrm{s}^{2}$, FM 1.00 $\mathrm{m} / \mathrm{s}^{2}$ and VF $0.88 \mathrm{~m} / \mathrm{s}^{2}$.

It comes out that RT total $\mathrm{a}_{\mathrm{v}}$ value is about $38 \%$ higher than $\mathrm{VF}$ that gave the lowest value. Regarding the A(8) daily values, calculated considering an effective duration of 7 hours, note that all the operating machines overcome the limit action value of $0.5 \mathrm{~m} / \mathrm{s}^{2}$. Even in this case RT has provided vibration values higher than about $34 \%$ compared to all the other operating machines. It follows that the maximum RT time of daily use is $0.99 \mathrm{~h}$, against the maximum time of use of the other machines ranging between 1.86 and 2.56.

\section{Wheeled tractor uphill (test T2-A)}

In the tests performed uphill (T2-A), RT gave the highest vibration value on the $\mathrm{z}$ axes $\left(0.99 \mathrm{~m} / \mathrm{s}^{2}\right)$, then we have CP $\left(0.57 \mathrm{~m} / \mathrm{s}^{2}\right), \mathrm{VF}(0.62$ $\left.\mathrm{m} / \mathrm{s}^{2}\right)$ and $\mathrm{FM}\left(0.45 \mathrm{~m} / \mathrm{s}^{2}\right)$. Note that FM shows a z-axis vibration value about $35 \%$ lower than the test performed in flat (T1-A). This difference could be attributed to the reduction of the forward speed from 3 to 2.5 $\mathrm{km} / \mathrm{h}$. Global weighted acceleration data and daily vibration exposure values are similar to those obtained in test T1-A.

\section{Wheeled tractor downhill (test T3-A)}

In the tests performed downhill (T3-A), RT gave the highest vibration value on the $\mathrm{z}$ axes $\left(0.88 \mathrm{~m} / \mathrm{s}^{2}\right)$, then we have CP $\left(0.60 \mathrm{~m} / \mathrm{s}^{2}\right), \mathrm{VF}$ $\left(0.58 \mathrm{~m} / \mathrm{s}^{2}\right)$ and FM $\left(0.58 \mathrm{~m} / \mathrm{s}^{2}\right)$. Note that FM shows a z-axis vibration value about $17 \%$ lower than the test performed in flat (T1-A) and $24 \%$ higher than those in T2-A. Global weighted acceleration data and daily vibration exposure values are similar to those obtained in tests T1-A and T2-A.

\section{Tests performed with the tracklying tractor}

\section{Tracklying tractor in flat (test T1-B)}

Data show that FM, RT and VF provided very similar z-axis value $\left(0.94 \mathrm{~m} / \mathrm{s}^{2}\right)$ ranging between 0.52 and $0.58 \mathrm{~m} / \mathrm{s}^{2}$. CP, however, showed lower values of about $36 \%$ compared to the previous machines. Regarding total $\mathrm{a}_{\mathrm{v}}$ value, FM and VF gave values about $22 \%$ higher than
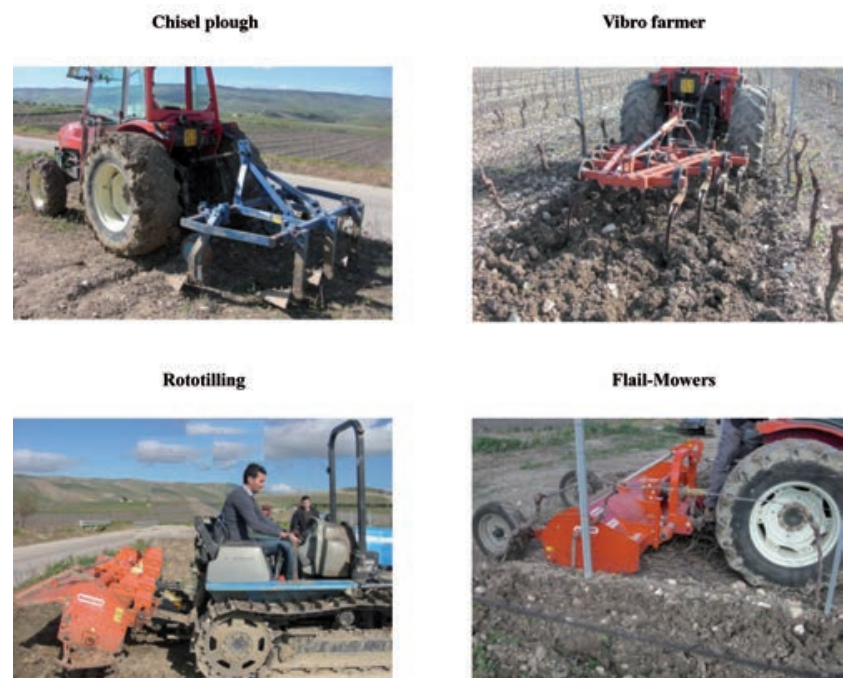

Figure 2. Machines used in the tests.

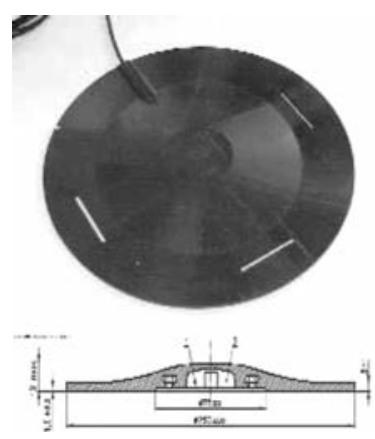

Figure 3. Triaxial accelerometer with adapter for the driving seat to measure whole-body vibrations.

a)
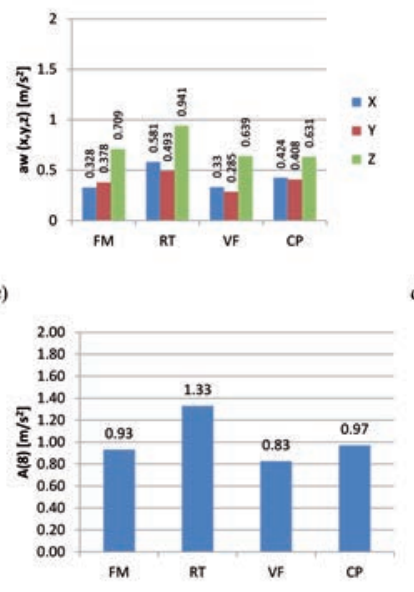

b)

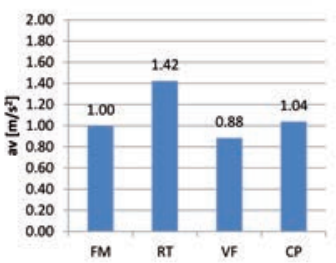

d)

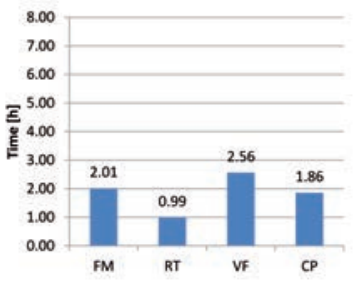

Figure 5. Frequency weighted vibration levels measured: a) on $x, y$ and $z$ axes; b) global weighted acceleration; c) daily vibration exposure value $A(8)$; d) maximum exposure time measured on the driver's seat of the wheeled tractor during the tests with Flail-Mowers (FM), Rototilling (RT), Vibro farmer (VF) and Chisel Plough (CP) in test T1-A. 
RT and CP. Concerning the A(8) daily values, note that all the operating machines overcome the limit action value of $0.5 \mathrm{~m} / \mathrm{s}^{2}$. FM and VF show the highest values $\left(0.98 \mathrm{~m} / \mathrm{s}^{2}\right)$ with a maximum time of daily use equal to $1.80 \mathrm{~h}$ respect to $2,56 \mathrm{~h}$ for $\mathrm{RT}$ and $2.99 \mathrm{~h}$ for $\mathrm{CP}$.

\section{Tracklying tractor uphill (test T2-B)}

In the tests performed uphill (T2-B), the four operating machines gave very similar $\mathrm{z}$ axis vibration values going from a minimum of 0.51 $\mathrm{m} / \mathrm{s}^{2}$ for FM to a maximum of 0.66 for RT. This is attributed to the reduction of the forward speed from 3 to $2.5 \mathrm{~km} / \mathrm{h}$. With reference to global weighted acceleration data, VF show a value about 18\% higher than FM and $\mathrm{CP}$ and about $10 \%$ higher than RT. The limit value of daily vibration exposure is exceeded by all the machines. VF and $\left(1.05 \mathrm{~m} / \mathrm{s}^{2}\right)$ and RT $\left(0.95 \mathrm{~m} / \mathrm{s}^{2}\right)$ gave the highest values with a maximum time of daily use respectively equal to $1.58 \mathrm{~h}$ and $1.95 \mathrm{~h}$.

\section{Tracklying tractor downhill (test T3-B)}

In the tests performed downhill (T3-B), RT gave the highest vibration value on the $\mathrm{z}$ axis $\left(0.74 \mathrm{~m} / \mathrm{s}^{2}\right)$, then we have FM and $\mathrm{CP}\left(0.5 \mathrm{~m} / \mathrm{s}^{2}\right)$, and $\mathrm{VF}\left(0.51 \mathrm{~m} / \mathrm{s}^{2}\right)$. The maximum of global weighted acceleration data was obtained in RT equal to $1.32 \mathrm{~m} / \mathrm{s}^{2}$. The other machines show lower values respect to RT of about $18 \%$ (CP), $21 \%$ (FM) and $28 \%$ (VF). The limit value of daily vibration exposure is exceeded by all the machines. RT and $\left(1.32 \mathrm{~m} / \mathrm{s}^{2}\right)$ and CT $\left(1.09 \mathrm{~m} / \mathrm{s}^{2}\right)$ gave the highest values with a maximum time of daily use respectively equal to $1.14 \mathrm{~h}$ and $1.46 \mathrm{~h}$.

Figure 11 shows one of several possible comparisons between the wheeled and the tracklying tractor time history both coupled with the rototilling.

Note that the highest peaks are in the $\mathrm{z}$ axis in the wheeled tractor (A), with $\mathrm{a}_{\mathrm{v}}$ values of $1.2-1.3 \mathrm{~m} / \mathrm{s}^{2}$. In tractor B the peak values never exceed $1 \mathrm{~m} / \mathrm{s}^{2}$.

\section{Conclusions}

The study carried out in order to assess the levels of whole body

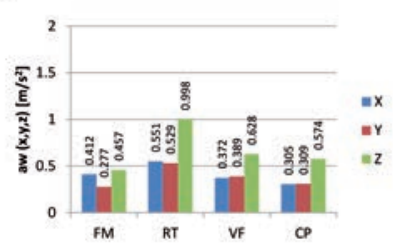

c)

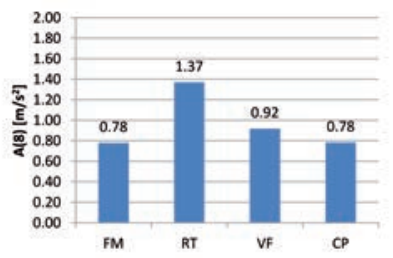

b)

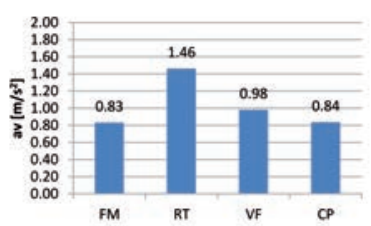

d)

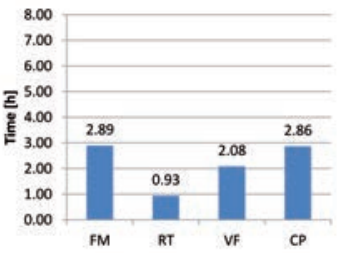

Figure 6. Frequency weighted vibration levels measured: a) on $x, y$ and $z$ axes; b) global weighted acceleration; c) daily vibration exposure value A(8); d) maximum exposure time measured on the driver's seat of the wheeled tractor during the tests with Flail-Mowers (FM), Rototilling (RT), Vibro farmer (VF) and Chisel Plough (CP) in test T2-A. vibration transmitted to the operator during the execution of the main tillage operations to the vineyard gave interesting results.

The use of four different operating machines as rototilling (RT), chisel plough (CP), flail mowers (FM) and vibro farmer (VF) coupled both with a wheeled and a tracklying tractor gave $\mathrm{A}(8)$ values always higher than $0.5 \mathrm{~m} / \mathrm{s}^{2}$ therefore, included in the "risk threshold" identified by the Italian Law Decree 81/2008. The employer, therefore, will have to apply the provisions aimed at avoiding or reducing vibration exposure of the worker as reported in Article 5 of Directive 2002/44/EC.

Finally, the results obtained allow to make the following considerations: a)
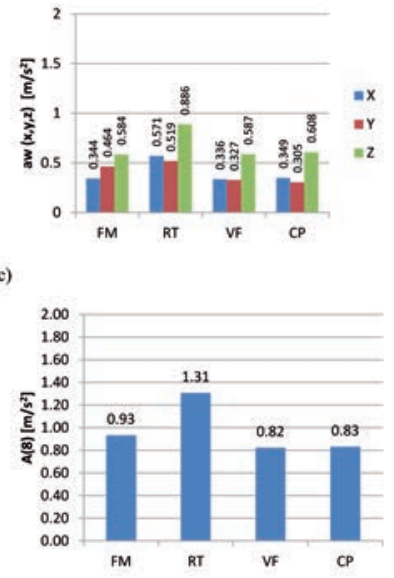
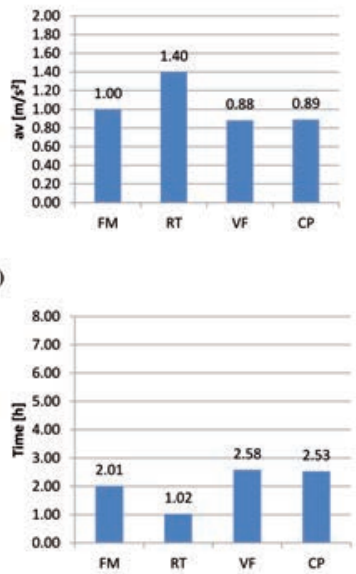

Figure 7. Frequency weighted vibration levels measured: a) on $x, y$ and $z$ axes; b) global weighted acceleration; c) daily vibration exposure value $A(8)$; d) maximum exposure time measured on the driver's seat of the wheeled tractor during the tests with Flail-Mowers (FM), Rototilling (RT), Vibro farmer (VF) and Chisel Plough (CP) in test T3-A. a)

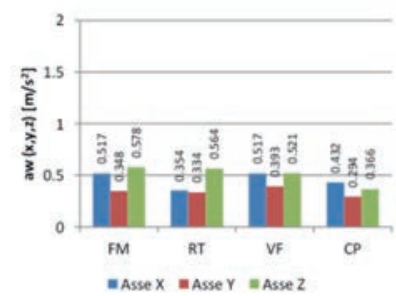

c)

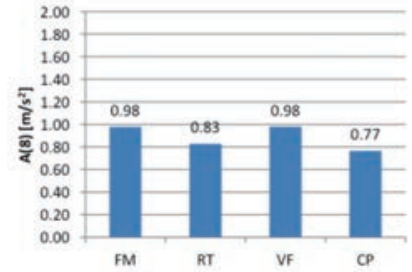

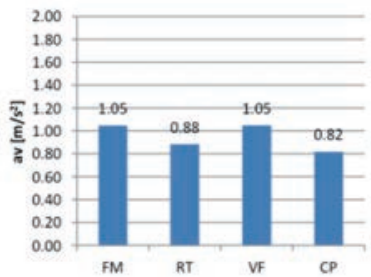

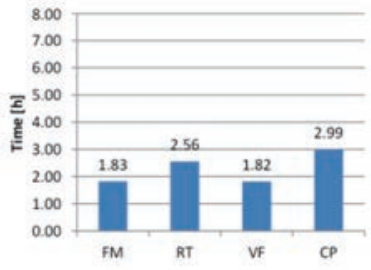

Figure 8. Frequency weighted vibration levels measured: a) on $x, y$ and $z$ axes; b) global weighted acceleration; c) daily vibration exposure value $A(8)$; d) maximum exposure time measured on the driver's seat of the tracklying tractor during the tests with Flail-Mowers (FM), Rototilling (RT), Vibro farmer (VF) and Chisel Plough (CP) in test T1-B. 

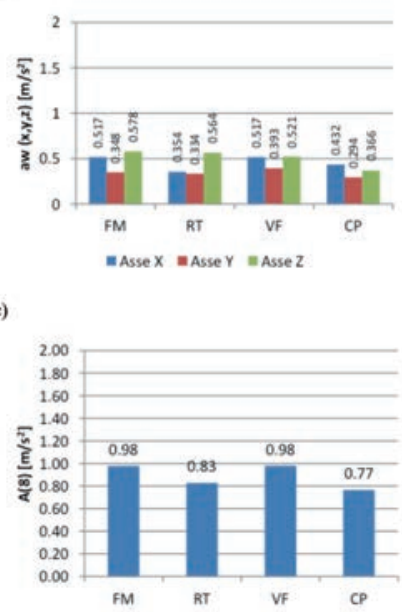

b)

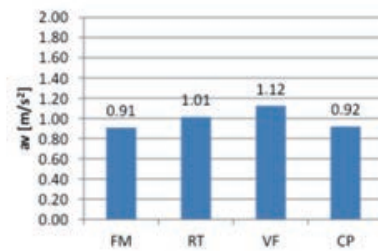

d)

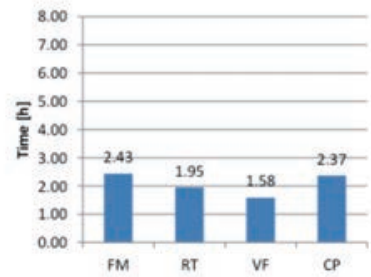

Figure 9. Frequency weighted vibration levels measured: a) on $x, y$ and $z$ axes; b) global weighted acceleration; c) daily vibration exposure value $A(8)$; d) maximum exposure time measured on the driver's seat of the tracklying tractor during the tests with Flail-Mowers (FM), Rototilling (RT), Vibro farmer (VF) and Chisel Plough (CP) in test T2-B.
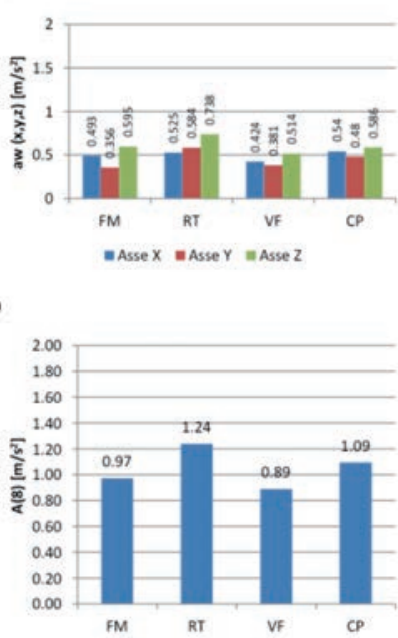

b)

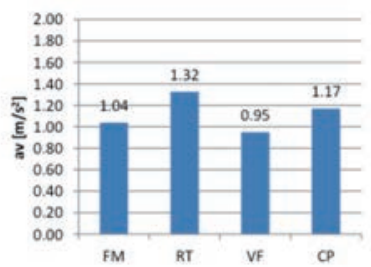

d)

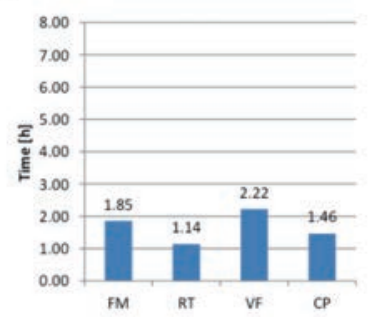

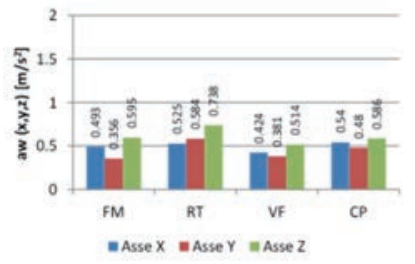

c)

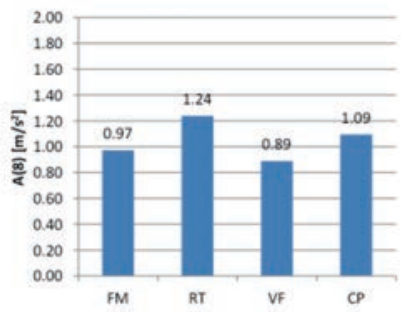

b)
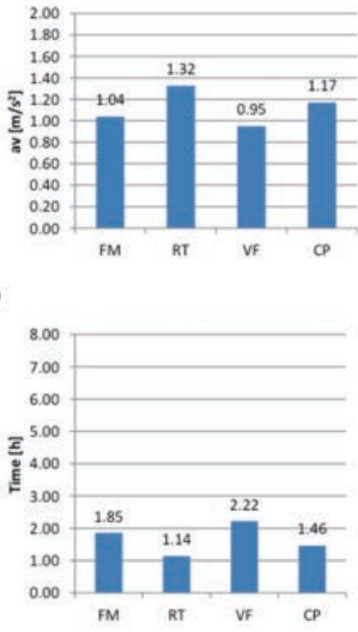

Figure 11. Time history of the vibration measurements on tractors $A$ and $B$ with rototilling in $\mathrm{T} 1$.

the machines coupled to the wheeled tractor always registered higher vibration values on the driving seat than the same machines coupled to the tracklying tractor. This may be attributed from the fact that the wheeled tractor has both a lower contact surface with the soil and a lower overall mass, about twice lower than the tracklying tractor;

the operating machines showing higher vibration values are rototilling and vibro farmer in both tractors;

the soil conditions in terms of slope caused no particular differences of vibration levels for all the machines used in the tests.

\section{References}

European Commission. 2002. European Directive of 25 June 2002 on the minimum health and safety requirements regarding the exposure of workers to the risks arising from physical agents (vibration) 2002/44/EC. In: Official Journal, L 177/13, 06/07/2002, 13-19.

ISO 2631-1, 2008. Mechanical Vibration and shock - Evaluation of Human Exposure to Whole-Body Vibration. Part - 1: General Requirements. International Standard Organization, Geneva.

Law Decree 81, 9 April 2008 of the Italian Republic.

Lines J.A., Stiles M., Whyte R.T. 1995. Whole body vibration during tractor driving. J Low Freq Noise Vib., 14(2), 87-104.

Matthews J. 1966. Ride comfort for tractor operators: II analysis of ride vibrations on pneumatic tyred tractors. J Agr Eng Res, 9(2), 14758 .

Pessina D., Facchinetti D., Bonalume V. 2012. Evaluation of vibration levels improves the efficiency of modern tracklaying tractors, XLIII, 43-47.

Scarlett A.J., Price J.S., Stayner R.M., 2007. Whole-body vibration: evaluation of emission and exposure levels arising from agricultural tractors. J. Terramechanics, 44, 65-73. 